\title{
BM-LEARNING EXPERIENCE IN CARRYING OUT FINAL DEGREE PROJECTS
}

\author{
L. Hojas Hojas, E.M. García Del Toro \\ Universidad Politécnica de Madrid, ETS Ingeniería Civil (SPAIN)
}

\begin{abstract}
The revolution that is taking place in the media and learning techniques in higher education is dizzying.

The COVID-19 pandemic has caused the teaching methodologies considered by many teachers to be experimental methods, in a few months, have been integrated into the regular activities of teachers.
\end{abstract}

The concept b-learning, (blended learning) has been introduced in a disruptive way at all educational levels and in particular in university education, and associated with it have appeared m-learning techniques.

The different level of equipment for students and teachers, the quality of communications and the widespread access to mobile phones have created the most extensive and developed collaboration network that we have had to date.

In many subjects the COVID-19 pandemic has caused a revolution in teaching.

In this work we want to show the adaptations that we have introduced in the way of developing an educational innovation project entitled "Design and Participation in Engineering" (UPM IE1920: 5803) highlighting the activities carried out in the two areas indicated b-learning and $\mathrm{m}$ - learning.

Perhaps the most significant of b-learning techniques has been the paradigm shift.

The student has focused the training process and has replaced the training offer model, carried out by the teacher, through the master class and laboratories for the on-demand model, which the student performs when encountering problems in understanding the concepts or in carrying out activities.

On the other hand, within the m-learning techniques, the massive use of social networks and educational applications has been implemented, which has made communications and training processes more open.

These work techniques have fostered student participation and the perception that training is a very valuable asset for them. Perhaps for teachers it has meant a very high increase in workload and especially the feeling that the workday never ends.

Keywords: Educational Innovation, COVID-19, m-learning, b-learning, Collaborative learning.

\section{INTRODUCTION}

Engineering education is changing very fast.

The exponential development of new technologies has caused traditional teaching to be increasingly inefficient in the training of engineers [1]. The modern engineer is a member of the team specialized in a technical area who has to collaborate in developing solutions with other specialists [2].

Engineers have to find solutions quickly and efficiently in changing environments [3]. The final degree project is the most useful tool available in current study plans to develop these skills.

The development of the end-of-degree project has to integrate three skills:

1 Develop innovative solutions by bringing together different people in different technical areas.

2 Introduce work methodologies oriented to productivity in the society of the XXI century.

3 Focus your work proposals on society, both by developing interesting proposals for social and economic agents and for entrepreneurship.

Another fundamental element is the way to assess the activities of the End of Degree Project, so that the qualification is determined by a series of activities such as: the technical quality of the project, the 
social participation determined by the dissemination that the projects have obtained and above all, the scope it has obtained in entrepreneurship programs such as the ActúaUPM program or other similar ones [4].

The pandemic that we are suffering is being an incentive to change our teaching practices immediately and an incentive to innovate in training processes. Which encourages the mass incorporation of communications and distributed collaborative work to develop teaching activities in this situation of limited mobility due to the risks of contagion of the disease [5].

The project that we present here is a tool that aims to prepare the new training methodologies in engineering, and in particular in civil engineering.

The School of Civil Engineering of the Polytechnic University of Madrid (UPM) is preparing the new curricula for the coming years and adapting the contents and methodologies to a new open and highly competitive society in which we are immersed.

The project is developed within the framework of the UPM's Teaching Innovation initiative entitled "Design and Participation in Engineering" IE1920: 5803.

The work is focused on the final degree project because it is the most flexible tool within the existing teaching programs in engineering studies at UPM.

\section{METHODOLOGY}

The major changes in the work procedure that are proposed are:

\subsection{Innovative Proposal}

A project has to be an innovative and creative solution in which several areas of engineering techniques participate [5].

\subsection{Productivity-oriented work methods}

Teams have to explicitly formalize work methodologies and guide activities to increase productivity and the use of communication technologies[6].

\subsection{Proposals aimed at submitting to entrepreneurship programs}

The proposals of the final degree projects must be interesting for society and be in a situation of application in the coming years [6].

The frame of reference for our work is the ActúaUPM program, but of course, any activity that pursues similar project development purposes is valid as a line of work [7].

In relation to the evaluation of the works, the goal is to introduce the objective indicators related to the results obtained by the project into the standard qualification procedures.

A good project will be one that meets the three criteria indicated above and the idea of the work is to use objective indicators for its qualification.

End-of-degree projects should serve to stimulate innovation in students, to create work networks based on new methodologies and to disseminate the project and study its impact both from an economic point of view and its social acceptance[8]

The work tools will be based on the intensive use of communication technologies. This idea, which is the leitmotif of the project, predates the COVID19 pandemic, but confinement or reduced mobility has caused it to become a basic need of the project. This catastrophic situation suffered by a large part of the population has been used to stimulate the incorporation of these techniques.

The work philosophy is to use the new frameworks called B-Learning (Blended Learning), and MLearning (Mobil Learning), in order to increase communications thanks to the tools available in current mobile phones.

The tools are divided into three groups:

- Communication tools

- Productivity Tools 
- Dissemination and Participation Tools.

Communication Tools are focused on the intensive use of computer tools:

- Work environments such as office 365 and google apps for education

- Broadcast environment such as blogger, wikispaces or google hangouts

- File sharing tools like Dropbox or google drive

- Resources to organize work such as workflowy or google calendar

- Tools for virtual meetings with Zoom or Skype

\subsection{Productivity Tools}

We have called productivity tools, a set of work techniques that make labor relations more flexible and, above all, facilitate the achievement of objectives through the availability of content [9]. In addition to developing the activities at the time that is most convenient for the students.

In this framework, some of the tools used are: Webinar, Design SPRINT, TRL or Design Thinking.

Webinars allow seminars and conferences on the topics to be held virtually and also allow them to be preserved on video platforms such as YouTube or Vimeo and on audio platforms such as ivoox, allowing them to be used over time. These seminars will be talks and debates of about 20 minutes to introduce the status of a technological topic and the possible orientations of the work to be carried out. The talks will have the objective of opening areas of work and collaboration between students and teachers.

Some of the topics proposed in these conferences are:

- Motorization of vehicles. Thermal, electrical and hybrid systems

- Autonomous driving. Industrial environment and urban environment

- Hyperlight transport. Diversity of low impact mobility alternatives

- The drone revolution

- Artificial Intelligence and Deep Learning applied to Civil Engineering

- Environmental Monitoring. Low cost detection systems.

- Engineering with mobiles. Use of mobiles in engineering.

Figure 1 shows the Posters to promote webinars.
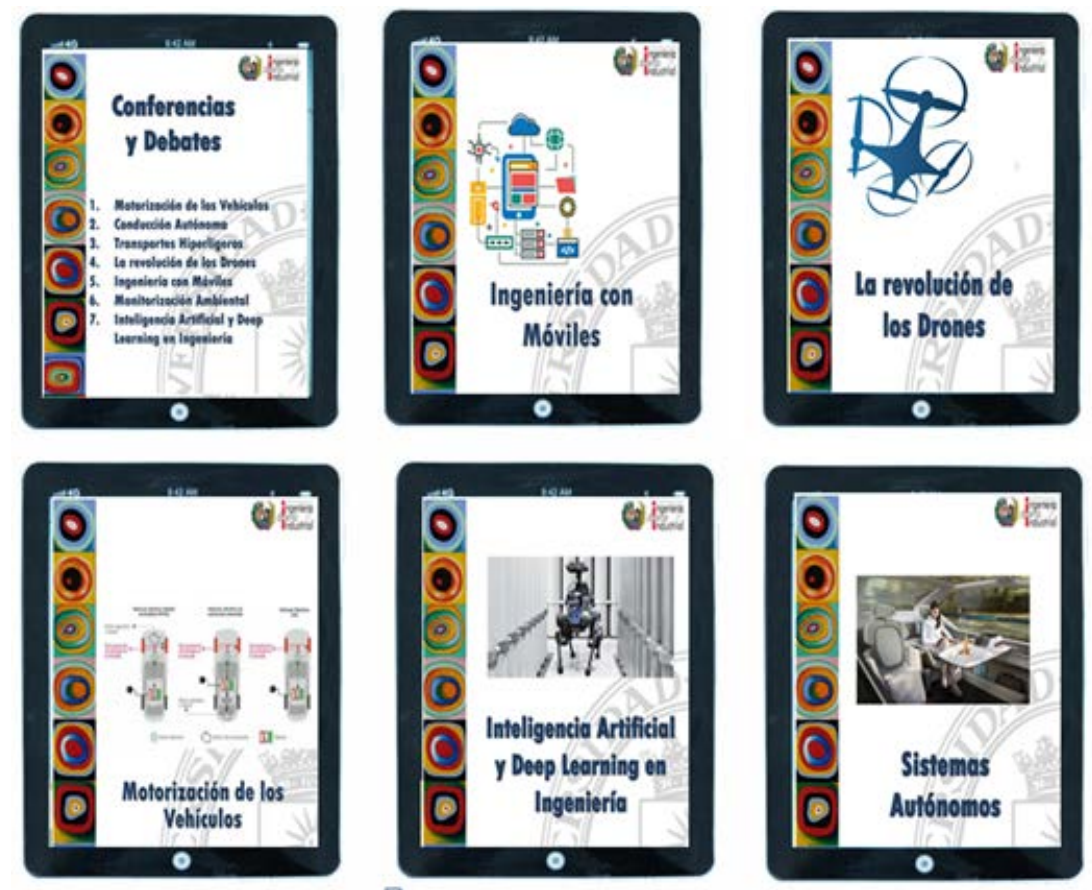

Figure 1: Posters to promote webinars 
Design SPRINT are agile work models that allow teams to form and develop content quickly and aimed at collaboration. The typical steps for the Design SPRINT application are as follows:

- Understand: Explain the relationships, alternatives and conflicts that exist

- Define: Expose the strategies to be used to find solutions

- Diverge: Open a wide framework of options to solve the problem

- Decide: Select a solution and plan work milestones

- Prototype: Implement the proposed solution (level determined by the activity)

- Document and Disseminate: Generate technical documentation and public information for the dissemination of the project.

As an example, this schedule is proposed for the development of Design SPRINT and can be seen in figure number 2:

- 1st day, morning: Discussion of the topics and choice of one

- 1st day, afternoon: Outlining the project

- 2nd day, tomorrow: Decide on the general work plan

- 2nd day, afternoon: Implement the basic elements of the proposal

- 3nd day, morning: Documentation of the activities carried out

- 3nd day, aflternoon: Documentation and Exhibition

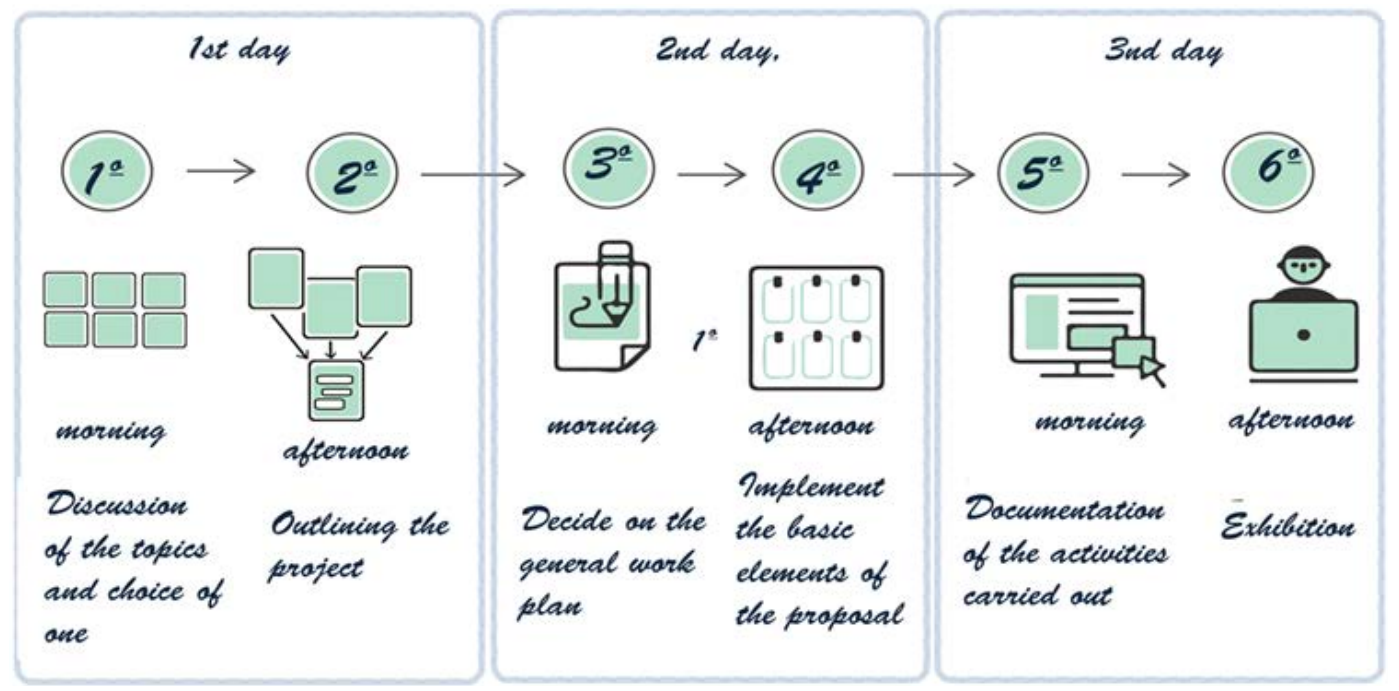

Figure 2: schedule scheme for the development of Design SPRINT

\subsection{TRL}

Tool to mark the milestones of the work and determine the results obtained in relation to those foreseen in the work plan.

TRL (Technology readiness levels) are a standardized procedure for analyzing the degree of development of a technology.

The application we are using is slightly modified to adapt it to our environment but it is similar to the one used in the framework of European projects.

The method consists of three divisions: Idea, Prototyping and Validation. Each of these divisions have some subdivisions that we have modified in the following way:

\subsubsection{Idea}

1 Formulation of an idea

2 Description of technologies 
3 Operational planning

\subsubsection{Prototyping}

4 Basic functionalities

5 Functionality tests

6 Integration of components

7 Validation in the laboratory

\subsubsection{Validation}

8 Minimum Viable Product Validation

9 Real Environment Testing

In figure 3 a graph of the phases that make up the process can be seen.
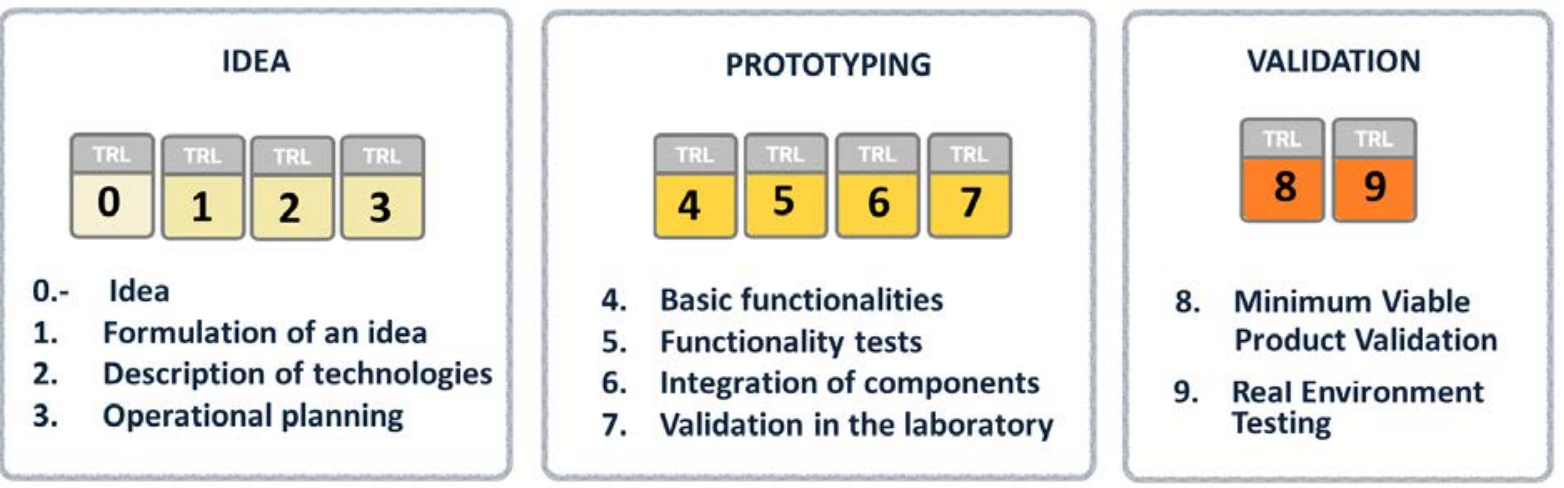

Figure 3: diagram of the phases of the TRL method

\subsection{Design Thinking}

Design Thinking is another of the tools aimed at optimizing work.

This methodology facilitates the activities for designers to systematically take into account the users or collaborating agents in the system design processes.

The main idea is that society and collaborating agents participate in the design and implementation tasks for the implementation of this technology.

Figure 4 shows a diagram of what the proposed process represents.

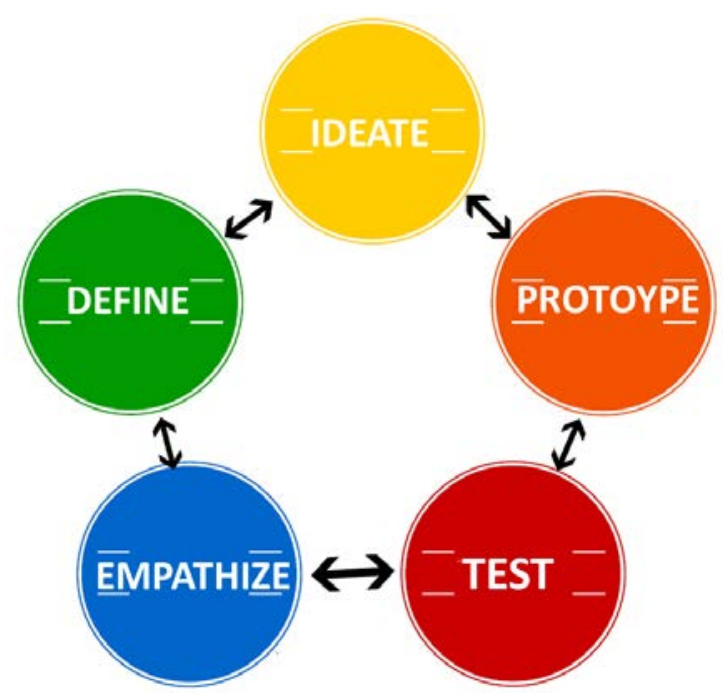

Figure 4: Design thinking diagram (source: Stanford school Design Thinking Process) 
Finally, dissemination and entrepreneurship will usually be carried out through the ActúaUPM program, although other options for university entrepreneurship programs are not ruled out either.

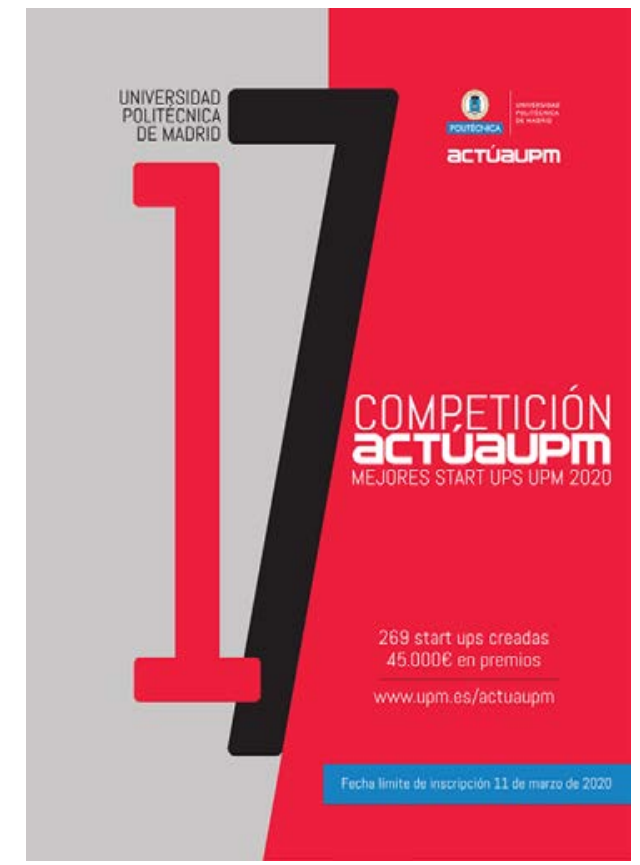

Figure 5: Poster announcing the Actúa UPM program (March 2020)

\section{RESULTS}

Due to the current pandemic situation that we are going through, the educative innovation projects proposed for the 2019-2020 and 2020-21 courses in the Universidad Politécnica de Madrid, do not follow their normal course. Therefore, the results proposed in this communication are the theoretical results that we hope to obtain. When the epidemiological situation subsides, we will be able to count on the actual results obtained and they will be able to be compared with those initially set in this paper.

The expected results of this approach to the activity are those indicated below:

1 Adaptation of teaching programs to the current socio-economic reality and in particular the final degree project as a tool for preparing for the reality of work.

2 Introduce the most current work methodologies such as collaborative tools and productivityoriented methodologies

3 Assessment of the work through the dissemination and the social and economic impact of the projects.

\section{CONCLUSIONS}

This work presents an educational innovation project developed within the framework of the activities of the Universidad Politécnica de Madrid. The main idea of the work is to establish a collaboration between engineering schools of different specialties in the Universidad Politécnica de Madrid, to develop joint end-of-degree projects. In them, the students of each of the disciplines could collaborate developing the knowledge acquired throughout their formative phase. The proposals final degree projects must be interesting for society and in a situation of application in the coming years.

End-of-degree projects should serve to stimulate innovation in students, to create work networks based on new methodologies and to disseminate the project, and study its impact both from an economic point of view and its social acceptance. The work's philosophy is to use the new frameworks called B-Learning (Blended Learning), and M-Learning (Mobil Learning).

Finally, the end-of-degree projects will be presented to the Actúa UPM entrepreneurship program that favors the creation of externalities of high educational and social value. 


\section{REFERENCES}

[1] C. Bravo, R. de Cózar, and C. Jiménez, "El uso de las nuevas tecnologías (TICS) en las aulas como factor predictivo del engagement en los estudios," in JUTE. Jornadas Universitarias de Tecnología Educativa., 2015, p. 2.

[2] D. Q. Naguyen, "The essential skills and atributes of Engineering: A comparative Study of Academic Industry Personnel and Enginerring Students.," Glob. J. Eng. Educ., vol. 2, pp. 65-76, 1998.

[3] Z. D. Zhang Y., Bai L., "Strengthening the Engineer's Lifelong Education.," Adv. Mater. Res., vol. 156-157, pp. 241-244., 2011.

[4] L. Vega Gónzalez, "La educación en ingeniería en el contexto global: propuesta para la formación de ingenieros en el primer cuarto del Siglo XXI," Ing. Investig. y Tecnol., vol. 14, no. 2, pp. 177190, 2013.

[5] M. R. García del Toro, E. M., Cerro Prada, E., Escolano Sanchez, F. García Salgado, S. Gónzalez gónzales, O., Heredia Molinero, C. Más López, M. I. Moya Hernández, A. E. Pérez Chamizo, R. M. Quijano Nieto, M. A. Vazquez Gallo, M. J., Torralba Marco, "Keepupmcivil: A online course for first year students in engineering and architecture degree," in 12th annual International Conference of Education, Research and Innovation, 2019, pp. 6358-6366.

[6] E. M. G. del T. Hojas Hojas I., "Final degree projects ad a tool for innovations and entrepreneurshipNo Title," in EDULEARN20 Proceedings, 2020, pp. 8786-8793,.

[7] Universidad Politécnica de Madrid, "ACTUA UPM," 2020. [Online]. Available: https://www.upm.es/Investigacion/innovacion/CreacionEmpresas/Servicios/Competicion_Creacion _Empresas. [Accessed: 13-Jan-2020].

[8] D. Azevedo, A., Apfelthaler, G., y Hurst, "Competency development in business graduates: An industry-driven approach for examining the alignment of undergraduate business education with industry requirements," Int. J. Manag. Educ., vol. 10, no. 1, pp. 12-28, 2012.

[9] R. Minaya Rodriguez, F. Hojas Hojas, I. García del toro Eva M., Pérez Chamizo, "Caja de Herramientas Formativas," in XVI Foro Internacional sobre Evaluación de la Calidad de la Educación Superior y la Investigación (FECIES), 2019, p. 100. 